\title{
Fuentes terrestres de contaminación que impactan la zona marino-costera del Golfo de Papagayo, Costa Rica
}

\section{Terrestrial sources of pollution impacting the marine- coastal zone of the Gulf of Papagayo, Costa Rica}

\author{
Ana Y. Saravia-Arguedas ${ }^{1 *}$, Gladys Margarita Lugioyo², Andrea Suárez Serrano ${ }^{3}$, \\ Anny Guillén Watson ${ }^{3}$ y Luis Sierra Sierra ${ }^{4}$
}

\begin{abstract}
RESUMEN
El Golfo de Papagayo, en los últimos años, ha experimentado un acelerado desarrollo socioeconómico que puede ejercer presión sobre sus espacios y recursos naturales, y contribuir, así, al deterioro de su zona marino-costera. Por lo tanto, el objetivo de este estudio fue identificar las principales fuentes terrestres de contaminación que puedan ejercer efectos negativos sobre el ambiente y la calidad higiénico-sanitaria de las aguas de sus playas. Para recolectar información sobre la producción y el manejo de los residuos sólidos y líquidos, generados por las actividades socioeconómicas que se desarrollan en los distritos costeros de Nacascolo y Sardinal, se aplicaron 81 encuestas a locales comerciales durante los años 2016 y 2017. Además, se realizaron cuatro muestreos de agua en diferentes playas. Los resultados indican que el $76 \%$ de establecimientos comerciales y el 50\% de hoteles disponen los residuos sólidos por medio del sistema de recolección de basura municipal; el $24 \%$ de comercios y el $81 \%$ de hoteles utilizan tanque séptico para la disposición de aguas residuales. Lo anterior, debido a que, por la naturaleza de las actividades, los residuos generados se consideran de tipo ordinario. Con respecto a las concentraciones de coliformes fecales, para determinar la calidad higiénicosanitaria se establecieron tres categorías: excelente $(<10)$, buena $(10-100)$ y regular (101-240). Para el caso de Enterococcus su concentración indica que todas las playas son aptas para la recreación. En general, las concentraciones de estos dos parámetros aumentaron en su mayoría durante la época lluviosa, probablemente debido a la escorrentía superficial.
\end{abstract}

Palabras clave: desechos sólidos, desechos líquidos, contaminación costera, coliformes totales, Enterococcus

1 Escuela de Química, Universidad Nacional de Costa Rica. Doctorado en Ciencias Naturales para el Desarrollo (DOCINADE), Instituto Tecnológico de Costa Rica, Universidad Nacional, Universidad Estatal a Distancias, Costa Rica. ana.saravia.arguedas@una.ac.cr*

2 Instituto de Ciencias del Mar (ICIMAR), calle Loma \# 14, entre 35 y 37, Plaza de la Revolución, La Habana, Cuba. margarita@cebimar.cu

3 HIDROCEC, Universidad Nacional de Costa Rica. andrea.suarez.serrano@gmail.com, anny.guillen.watson@una. ac.cr

4 Escuela de Ciencias Biológicas, Universidad Nacional de Costa Rica. luis.sierra.sierra@una.ac.cr 


\section{ABSTRACT}

In recent years, the Gulf of Papagayo has been experiencing accelerated socio-economic development that may be putting pressure on its natural spaces and resources, contributing to the deterioration of its marine-coastal zone. The objective of this study was to identify the main terrestrial sources of pollution that may have negative effects on the environment and the hygienic-sanitary quality of the waters at its beaches. In order to collect information on the production and management of solid and liquid waste, generated by the socio-economic activities carried out in the coastal districts of Nacascolo and Sardinal, 81 surveys were applied to commercial premises during 2016 and 2017. In addition, four water samples were taken from different beaches. Results indicate that $76 \%$ of the commercial establishments and $50 \%$ of the hotels dispose of solid waste through the municipal garbage collection system, while $24 \%$ of the shops and $81 \%$ of the hotels use septic tanks for disposal of sewage. This is due to the fact that, because of the nature of these activities, the waste generated is considered ordinary. Regarding the concentrations of fecal coliforms, three categories were established in order to determine the hygienic-sanitary quality: excellent $(<10)$, good (10-100), and regular (101-240). In the case of Enterococcus, its concentration indicates that all beaches are suitable for recreation. In general, the concentrations of these two parameters increased mostly during the rainy season, probably due to surface runoff.

Keywords: solid waste, liquid waste, coastal pollution, total coliforms, Enterococcus

\section{INTRODUCCIÓN}

En la zona noroccidental del $\mathrm{Pa}$ cífico Norte de Costa Rica, se ubica el Golfo de Papagayo, el cual se extiende desde Punta Gorda (Playa Ocotal) hasta Cabo Santa Elena, es mucho más abierto que los golfos de Nicoya y Golfo Dulce, su extensión es de $180 \mathrm{Km}^{2}$ (Duffy \& Frazier, 2014). Su parte norte está bajo el Sistema de Parques Nacionales y abarca tres distritos (Santa Elena, Nacascolo y Sardinal) de tres cantones (La Cruz, Liberia y $\mathrm{Ca}$ rrillo) de la provincia de Guanacaste. Su geomorfología está compuesta por penínsulas, cabos, acantilados rocosos interrumpidos por playas arenosas y rocosas, pequeñas cuencas, cerros, entre otros (Reyes et al. 2015).
Una particularidad la constituyen el afloramiento costero y la formación del domo térmico debido a la influencia de los vientos alisios originarios del Caribe, forzados hacia el Pacífico por el traslado de la Zona de Convergencia Intertropical (ZCIT) (Jiménez, 2016). Ello permite que exista una elevada abundancia de zooplancton y biomasa planctónica (May-Collado \& Forcada, 2012), la cual favorece la alta productividad y diversidad de hábitats y especies de corales, moluscos, cnidarios, peces y cetáceos (BIOMARCC-SINAC-GIZ, 2013; Cortés, 2017), tales como el delfín esteno (Steno bredanensis), la ballena piloto (Globicephala) y las orcas (Orcinus orca) (May-Collado et al. 2018). 
En los últimos años, el incremento de actividades socioeconómicas de esta zona se ha acelerado, aumentando la presión de uso de espacios y recursos naturales, para la generación de ingresos y recreación; lo cual, de acuerdo con Doria \& Vivas (2016), juega un papel importante en el deterioro de los recursos naturales. Así mismo, Sánchez-Noguera et al. (2018) indican que existe una estrecha interdependencia y relación entre los componentes sociales y ecológicos de las zonas costeras, que conlleva a que las poblaciones locales deban ir adaptándose a los cambios que ocurren en sus alrededores, tales como la disminución en la distribución y productividad de especies pesqueras importantes, la intrusión marina, inundación de tierras residenciales y agrícolas, pérdidas potenciales en el valor del turismo, alteración de la calidad de las aguas y del lecho oceánico, en detrimento de los hábitats marinos como arrecifes de coral y playas.

Muchos de estos cambios se pueden incrementar por el transporte de desechos (sólidos y líquidos) a través de los ríos, estuarios, canales u otros cuerpos de agua, generados en las diferentes fuentes de contaminación ubicadas en las franjas costeras y en el mar (Doria \& Vivas, 2016). Los sólidos que llegan a las zonas costeras, como el plástico, han provocado un grave problema en el medio marino (Socas, 2018). De la misma manera, las aguas residuales domésticas y negras pueden contener materia orgánica, sólidos en suspensión, grasas y aceites, además de microorganismos que conllevan a una elevada concentración de bacterias patógenas como Shigella, cepas de Salmonella spp, Vibrio spp, Staphilococcus aureus, Streptoccus spp, entre otros. Igualmente, puede darse la presencia de otros organismos como protozoos y virus, que representan un riesgo potencial para la salud de bañistas y público consumidor de moluscos bivalvos contaminados (Reyes, 2016).

En esta zona de estudio existen datos de promedios geométricos de coliformes fecales de algunas playas, por ejemplo, Mora et al. (2012) determinaron para las playas Nacascolo, Panamá, Ocotal, Hermosa, El Coco, para el período de 1996 a 2011, concentraciones promedio de $3 \mathrm{CF} / 100 \mathrm{~mL}, 6 \mathrm{CF} / 100$ $\mathrm{mL}, 9 \mathrm{CF} / 100 \mathrm{~mL}, 14 \mathrm{CF} / 100 \mathrm{~mL}$ y 10 $\mathrm{CF} / 100 \mathrm{~mL}$, respectivamente. De igual modo, Sánchez-Noguera et al. (2018) encontraron en las playas Panamá, Esmeralda, Blanca y Sombrero, en el período de octubre de 2010 a junio del 2011, concentraciones de coliformes fecales de $2.5 \mathrm{CF} / 100 \mathrm{~mL}$ a $17.4 \mathrm{CF} / 100$ $\mathrm{mL}$. En ambos estudios la calidad de las aguas de esas playas fue considerada, entre excelente y buena, lo que las clasifica como aguas aptas para la natación.

Con el fin de determinar si, en la actualidad, existe un deterioro de la zona marino-costera del Golfo de Papagayo debido a las actividades económicas que en este momento se están 
desarrollando en esta zona, el propósito de este trabajo fue identificar las fuentes de contaminación terrestres que puedan generar efectos negativos sobre el ambiente, así como determinar la calidad higiénico-sanitaria de las aguas de las playas.

\section{MATERIALES Y MÉTODOS}

La metodología de este estudio fue estructurada con base en dos aspectos: i) recopilación de información primaria y secundaria a través de instituciones como: las municipalidades de los cantones de Liberia y Carrillo y ii) el desarrollo de visitas de campo (inspección visual, registro fotográfico, aplicación de instrumentos de consulta, geoposicionamiento satelital y toma de muestras de agua en las playas seleccionadas para la determinación de calidad higiénico-sanitaria).

Para la recopilación de la información se tomaron como base los permisos de actividad comercial registrados en las municipalidades de los cantones de Liberia y Carrillo, con el fin de contar con un panorama real del tipo de actividades económicas que se desarrollan en los distritos costeros de Nacascolo y Sardinal. Una vez identificados los tipos de actividades, se realizó una delimitación de una franja angosta (Fig. 1), la cual representa un área total de 32860 hectáreas. Se realizaron cinco visitas de campo durante los meses de junio y julio del 2016, para la aplicación de encuestas con preguntas dirigidas al tipo de residuos que generan y su disposición final.

El análisis de la información relacionada con la producción y el manejo de los residuos sólidos; residuos líquidos; prácticas ambientales (reciclaje); ocupación de los hoteles, según estación del año, sirvió para la identificación de fuentes de contaminación de la zona marino-costera de estudio. Utilizando datos de población del INEC (2014) y datos del manejo de desechos sólidos por municipalidad, se calculó la producción anual de desechos sólidos en ton/año y, utilizando el índice de producción de aguas negras de 180 L/hab/día propuesto por León \& Jiménez (1998), se calculó la producción de desechos líquidos en $\mathrm{m}^{3} / \mathrm{año}$.

Para evaluar la calidad higiénico-sanitaria de las aguas costeras, se establecieron estaciones de muestreo que tuvieran en cuenta el interés de contar con datos homogéneos de todo el golfo. Se realizaron cuatro muestreos entre los meses de octubre del 2017 y mayo del 2018, durante las épocas seca y lluviosa, en 13 estaciones distribuidas a lo largo de la costa del Golfo de Papagayo (Cuadro 1). En todos los muestreos se determinó el número más probable presente en $100 \mathrm{~mL}$ de muestra de agua de mar, tanto de coliformes fecales como de Enterococcus, indicadores biológicos utilizados para determinar calidad sanitaria en agua de mar (Mora et al. 2012). 


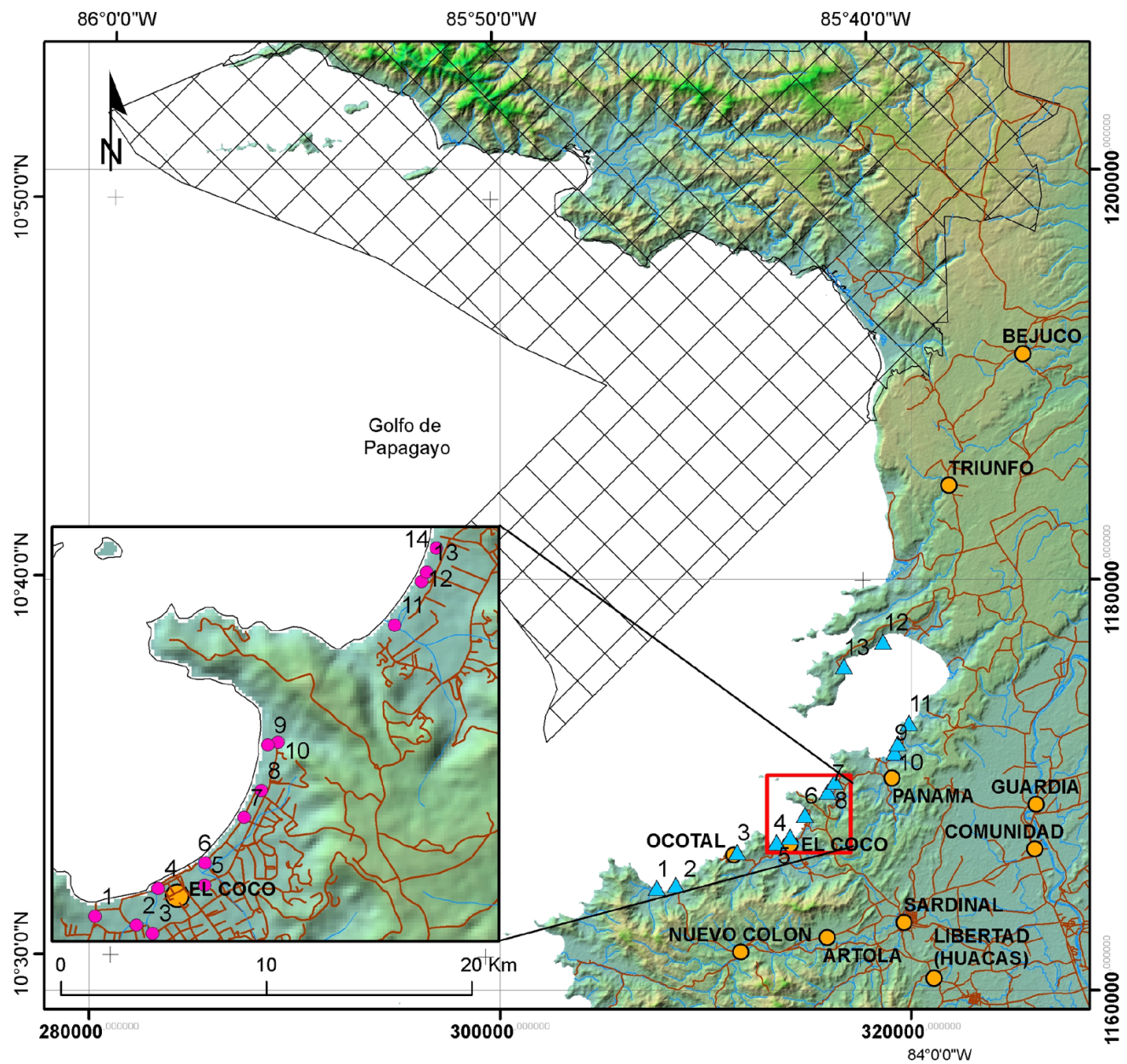

\section{Simbología}

$\triangle$ Muestreo microbiológico

- Vertidos de aguas

Poblados

- Ríos y quebradas

Caminos principales

$\square$ Área silvestre protegida
Grilla en el sistema de coordenadas CRTMO5 y cruces en coordenadas geográficas del datum WGS84.
Caminos, poblados, rios según el Atlas Digital del ITCR 2014.
Limite del Parque Nacional Santa Rosa según el SIG de ACG Cuencas gereradas utilizando el modelo de elevación digital SRTM de $30 \mathrm{~m}$. Se muestran en color inicamente las cuencas y microcuencas ( $>10 \mathrm{ha}$ ) que
desembocan directamente al Golfo de Papagayo.

Fig. 1. Localización del Golfo de Papagayo. Durán, 2016

Fig. 1. Location of the Gulf of Papagayo. Durán, 2016 
En cada estación de muestreo se colectó por duplicado $100 \mathrm{~mL}$ de agua de mar en frascos estériles a una profundidad aproximada de $30 \mathrm{~cm}$ por debajo de la superficie y contracorriente, y a una distancia de la línea de la costa en la que el agua llegara al nivel del pecho. Las muestras fueron trasladadas al Laboratorio de Microbiología
Ambiental del HIDROCEC-UNA Liberia, en hieleras a una temperatura aproximadamente de $\pm 4^{\circ} \mathrm{C}$, para su posterior análisis dentro de un lapso menor a 24 horas.

Para la determinación y cuantificación de coliformes fecales se empleó la metodología 9221 , correspondiente a la técnica de tubos de fermentación

Cuadro 1. Playas en donde se ubicaron los puntos de muestreo para el análisis de indicadores bacterianos

Table 1. Beaches where sampling points were located for the analysis of bacterial indicators

\begin{tabular}{|c|c|c|c|c|}
\hline \multirow{2}{*}{ Punto } & \multirow{2}{*}{ Lugar } & \multicolumn{2}{|c|}{ Coordenadas geográficas } & \multirow{2}{*}{ Descripción } \\
\hline & & Longitud & Latitud & \\
\hline 1 & Playa Matapalo Sur & $85^{\circ} 45^{\prime} 26^{\prime \prime} \mathrm{O}$ & $10^{\circ} 31^{\prime} 51^{\prime \prime} \mathrm{N}$ & $\begin{array}{l}\text { Frente segunda entrada de lastre } \\
\text { a la playa. }\end{array}$ \\
\hline 2 & $\begin{array}{l}\text { Playa Matapalo } \\
\text { Norte }\end{array}$ & $85^{\circ} 44^{\prime} 55^{\prime \prime} \mathrm{O}$ & $10^{\circ} 31^{\prime} 56^{\prime \prime} \mathrm{N}$ & Frente al hotel RIU. \\
\hline 3 & Playa Ocotal & $85^{\circ} 43^{\prime} 18^{\prime \prime} \mathrm{O}$ & $10^{\circ} 32^{\prime} 48^{\prime \prime} \mathrm{N}$ & Frente salida de agua (riachuelo). \\
\hline 4 & Playas del Coco Sur & $85^{\circ} 42^{\prime} 15^{\prime \prime} \mathrm{O}$ & $10^{\circ} 33^{\prime} 04^{\prime \prime} \mathrm{N}$ & $\begin{array}{l}\text { Frente carretera hacia playa } \\
\text { Ocotal. }\end{array}$ \\
\hline 5 & $\begin{array}{l}\text { Playas del Coco } \\
\text { Centro }\end{array}$ & $85^{\circ} 41^{\prime} 53^{\prime \prime} \mathrm{O}$ & $10^{\circ} 33^{\prime} 13^{\prime \prime} \mathrm{N}$ & Frente al parque Central. \\
\hline 6 & $\begin{array}{l}\text { Playas del Coco } \\
\text { Norte }\end{array}$ & $85^{\circ} 41^{\prime} 30^{\prime \prime} \mathrm{O}$ & $10^{\circ} 33^{\prime} 48^{\prime}, \mathrm{N}$ & Diagonal a salida de alcantarilla. \\
\hline 7 & Playa Hermosa Sur & $85^{\circ} 40^{\prime} 54^{\prime \prime} \mathrm{O}$ & $10^{\circ} 34^{\prime} 25^{\prime \prime} \mathrm{N}$ & Diagonal a salida de estero. \\
\hline 8 & $\begin{array}{l}\text { Playa Hermosa } \\
\text { Norte }\end{array}$ & $85^{\circ} 40^{\prime} 43^{\prime \prime} \mathrm{O}$ & $10^{\circ} 34^{\prime} 41^{\prime \prime} \mathrm{N}$ & $\begin{array}{l}\text { Frente restaurante "La casita del } \\
\text { Marisco". }\end{array}$ \\
\hline 9 & Playa Panamá Sur & $85^{\circ} 39^{\prime} 07^{\prime \prime} \mathrm{O}$ & $10^{\circ} 35^{\prime} 28^{\prime \prime} \mathrm{N}$ & $\begin{array}{l}\text { Frente a } 1^{\text {era }} \text { entrada carretera } \\
\text { desde playa hermosa. }\end{array}$ \\
\hline 10 & Playa Panamá Norte & $85^{\circ} 39^{\prime} 07^{\prime \prime} \mathrm{O}$ & $10^{\circ} 35^{\prime} 42^{\prime} \mathrm{N}$ & $\begin{array}{l}\text { Frente a } 2^{\text {da }} \text { entrada carretera } \\
\text { desde playa hermosa. }\end{array}$ \\
\hline 11 & Playa Arenilla & $85^{\circ} 38^{\prime} 44^{\prime \prime} \mathrm{O}$ & $10^{\circ} 36^{\prime} 14^{\prime \prime} \mathrm{N}$ & $\begin{array}{l}\text { Frente a hotel Secret, diagonal a } \\
\text { salida de agua de alcantarilla. }\end{array}$ \\
\hline 12 & $\begin{array}{l}\text { Marina Bahía } \\
\text { Culebra }\end{array}$ & $85^{\circ} 39^{\prime} 26^{\prime \prime} \mathrm{O}$ & $10^{\circ} 38^{\prime} 23^{\prime \prime} \mathrm{N}$ & Salida de marina. \\
\hline 13 & $\begin{array}{l}\text { Playa Nacascolo } \\
\text { Central }\end{array}$ & $85^{\circ} 40^{\prime} 29^{\prime \prime} \mathrm{O}$ & $10^{\circ} 37^{\prime} 43^{\prime \prime} \mathrm{N}$ & Frente a la playa. \\
\hline
\end{tabular}


múltiple para miembros del grupo de coliformes, descrita en el método estándar (APHA, 2012). Este método divide el proceso de detección en dos etapas: fase presuntiva y fase de confirmación. Para determinar la fase presuntiva para cada una de las muestras colectadas, se utilizaron cinco tubos de ensayo $10 \mathrm{~mL}$ del caldo de cultivo Lauril Triptosa $\left(\mathrm{OXOID}^{\mathrm{TM}}\right)$ por cada dilución empleada: $10 \mathrm{~mL}, 1 \mathrm{~mL}$ y 0.1 mL. Además, dentro de cada tubo de ensayo se le adicionó una campana de Durham invertida. Los tubos de ensayo que resultaron positivos (presencia de gas y turbiedad dentro de la campana de Durham), luego de una incubación a $35^{\circ} \mathrm{C}$ por un máximo de 48 horas, eran seleccionados para realizar la fase de confirmación. Esta última fase consistió en trasladar $60 \mu \mathrm{L}$ del caldo del tubo positivo a un nuevo tubo de ensayo conteniendo $10 \mathrm{~mL}$ de caldo de cultivo EC (OXOID ${ }^{\mathrm{TM}}$ ) para su posterior incubación a $44.5^{\circ} \mathrm{C}$ durante 24 horas. Los tubos positivos resultantes (mismo criterio del sistema que fase presuntiva) eran anotados y comparados con el "Índice NMP" del método estándar, de acuerdo con las características del ensayo (diluciones con cinco tubos), para la determinación de la concentración correspondiente (NMP/100 mL).

\section{La determinación} $\mathrm{y}$ cuantificación del indicador biológico Enterococcus se llevó a cabo mediante el ensayo de sustrato fluorogénico de Enterococcus, también descrito en el método estándar (9230D) (APHA, 2012). Para ello, se utilizó la formulación del sustrato fluorogénico comercial llamado Enterolert $^{\mathbb{B}}$ (IDEXX Laboratories, West-brook, ME), el cual se mezcló con una dilución 1:10 (10 $\mathrm{mL}$ de muestra de agua mar y $90 \mathrm{~mL}$ de agua destilada estéril). El volumen final $(100 \mathrm{~mL})$ fue incorporado y sellado dentro de una bandeja multipocillos Quanti-Tray ${ }^{\circledR} / 2000$ de 49 pocillos, siguiendo las instrucciones de la casa comercial IDEXX. Finalmente, se incubó las muestras a $41^{\circ} \mathrm{C}$ durante 24 horas. Transcurrido el tiempo, se examinó cada bandeja en oscuridad utilizando una lámpara ultravioleta (366 $\mathrm{nm}$ ), para detectar los pocillos positivos (con fluorescencia). A partir de este resultado, se calculó el NMP/100 mL usando la tabla provista por la casa comercial (IDEXX) considerando la dilución aplicada.

Para categorizar las playas se utilizó la clasificación propuesta por Mora et al. (2012), empleada por el Laboratorio Nacional de Aguas del Instituto Costarricense de Acueductos y Alcantarillados, que se basa en definir clases según la concentración de coliformes fecales (Cuadro 2).

Para los Enterococcus se empleó la propuesta de la Organización Mundial de la Salud (OMS) (Díaz et al. 2010), en donde los criterios de clasificación de las playas son concentraciones entre 0 y $500 \mathrm{NMP} / 100 \mathrm{~mL}$ "apta 
Cuadro 2. Número más probable de coliformes fecales en las playas ubicadas en los alrededores del Golfo de Papagayo, durante la época seca y lluviosa Table 2. Most probable number of fecal coliforms on the beaches along the Gulf of Papagayo, during dry and rainy seasons

\begin{tabular}{|c|c|c|c|c|c|}
\hline \multirow{3}{*}{ Punto } & \multirow{3}{*}{ Playa } & \multicolumn{2}{|c|}{ Época seca } & \multicolumn{2}{|c|}{ Época lluviosa } \\
\hline & & \multicolumn{4}{|c|}{ NMP/100 mL } \\
\hline & & nov-17 & feb-18 & oct-17 & may-18 \\
\hline 1 & Matapalo & $<1.8$ & $<1.8$ & $<1.8$ & 34.0 \\
\hline 2 & Matapalo & 13.0 & $<1.8$ & 4.0 & 23.0 \\
\hline 3 & Ocotal & 4.5 & $<1.8$ & 4.5 & 11.0 \\
\hline 4 & El Coco & 9.3 & 13.0 & $<1.8$ & 33.0 \\
\hline 5 & El Coco & 8.3 & $<1.8$ & 63.0 & 46.0 \\
\hline 6 & El Coco & $<1.8$ & $<1.8$ & 49.0 & 7.8 \\
\hline 7 & Hermosa & 70.0 & $<1.8$ & 79.0 & 2.0 \\
\hline 8 & Hermosa & 7.8 & 1.8 & 13.0 & 31.0 \\
\hline 9 & Panamá & $<1.8$ & 2.0 & 4.5 & $<1.8$ \\
\hline 10 & Panamá & 11.0 & $<1.8$ & 49.0 & 11.0 \\
\hline 11 & Arenilla & $<1.8$ & $<1.8$ & 240.0 & $<1.8$ \\
\hline 12 & Marina en Bahía Culebra & $<1.8$ & $<1.8$ & $<1.8$ & $<1.8$ \\
\hline 13 & Nacazcol & $<1.8$ & $<1.8$ & 1.8 & 2.0 \\
\hline
\end{tabular}

para uso recreativo“ y $>500 \mathrm{NMP} / 100$ $\mathrm{mL}$ "no es apta para uso recreativo".

\section{RESULTADOS Y DISCUSIÓN}

Según información suministrada por las diferentes municipalidades, el comercio es una actividad a pequeña escala que satisface la demanda local en el área de estudio. Al año 2016 existían 3376 permisos de actividades comerciales registrados en Liberia y 374 en Carrillo. En la Figura 2, se puede observar la distribución porcentual de las principales actividades económicas que se desarrollan en estos cantones, las cuales se agruparon en cinco categorías según su afinidad, en donde los mayores porcentajes (de $26 \%$ a $43 \%$ ) corresponden a la venta de productos y materiales, que incluyen almacenes, supermercados, bazares; seguido por la venta y prestación de servicios (de $24 \%$ a $34 \%$ ), que contemplan centros de enseñanza, salas de juego, agencias, entre otros.

Tomando en cuenta la información anterior y la delimitación de la franja costera para este estudio, se determinó que la cantidad aproximada de permisos en los distritos de Nacascolo y Sardinal, era de 60 y 300 respectiva- 


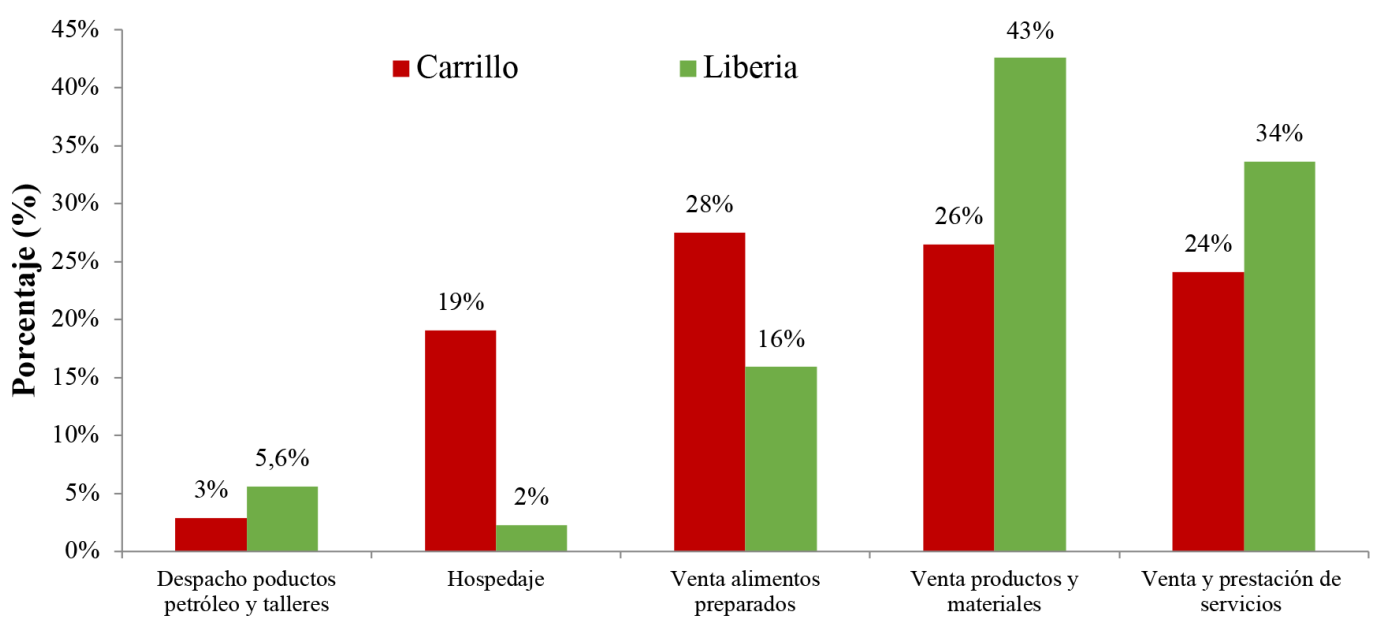

Actividades económicas

Fig. 2. Distribución porcentual por categoría de las principales actividades económicas de los cantones Liberia y Carrillo

Fig. 2. Percentage distribution by category of the main economic activities of the cantons of Liberia and Carrillo

mente. Es importante indicar que existen establecimientos que cuentan con más de un permiso comercial vigente.

Las encuestas confeccionadas se aplicaron en 81 locales comerciales, de los cuales el $57 \%$ fueron heladerías, restaurantes y bares que se dedican a la venta de alimentos preparados; el 10\% correspondió a establecimientos dedicados a la venta de productos y materiales, tales como: carnicerías, productos agropecuarios, supermercados; y el $33 \%$ al servicio de hospedaje (hoteles y hostales). De la sistematización de dichas encuestas se observa que, por la naturaleza de las actividades que se desarrollan, los residuos sólidos son considerados como de tipo ordinario (papel, plástico, entre otros) y que el $76 \%$ de establecimientos comerciales y el $50 \%$ de los hoteles los disponen por medio del servicio de recolección de basura que ofrecen las diferentes municipalidades (Fig. 3).

Nacascolo produce anualmente 503 ton y Sardinal 3342 ton de residuos, en donde los sistemas de disposición final por parte de las municipalidades son en rellenos sanitarios ubicados en Liberia y Carrillo. Debido a que, de estos dos distritos, Sardinal es el que cuenta con la menor área $\left(210.38 \mathrm{Km}^{2}\right)$ y con la mayor cantidad de población (14 912 hab) (INEC, 2014), resulta más propenso a inducir la contaminación del área 


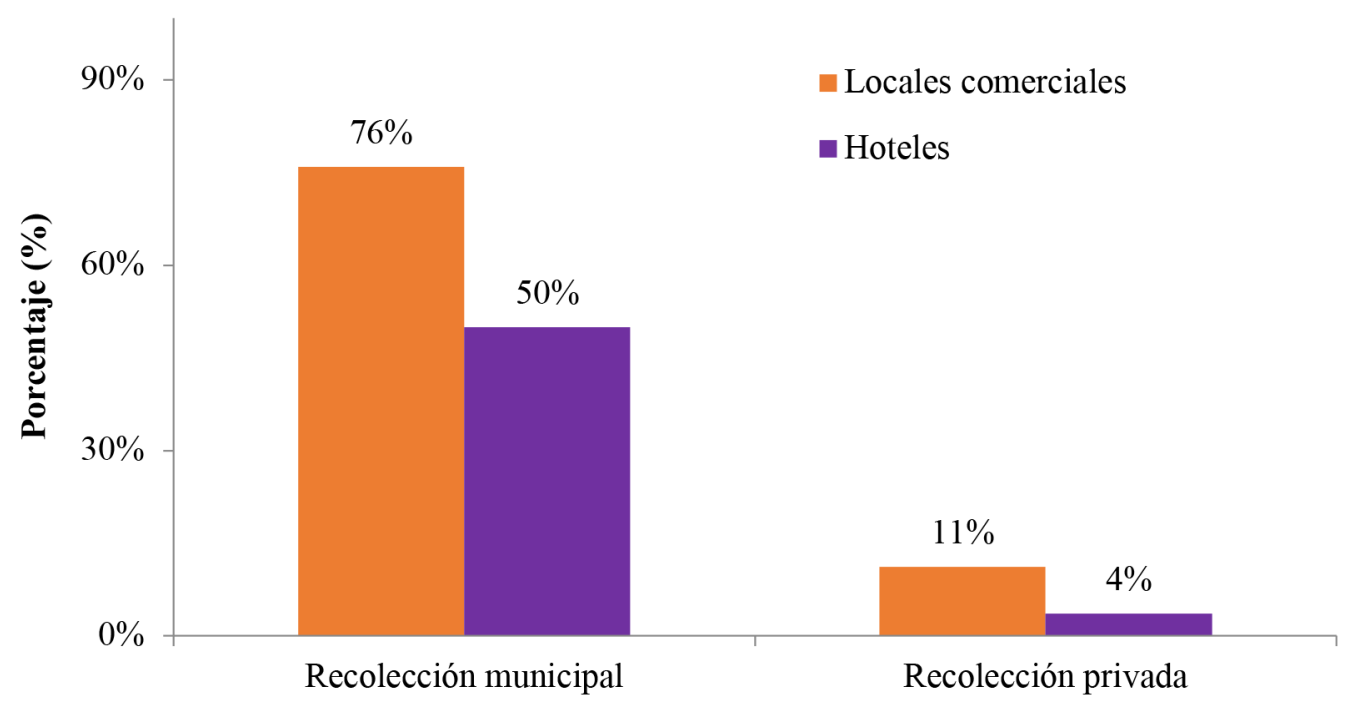

Tipo de disposición de residuos sólidos

Fig. 3. Disposición porcentual de la disposición de residuos sólidos, por categoría de las principales actividades económicas de los distritos Nacascolo y Sardinal Fig. 3. Percentage disposition of solid waste disposal, by category of the main economic activities of the Nacascolo and Sardinal districts

marino-costera, si sus residuos no son dispuestos correctamente.

Así mismo, se desprende que solo el $31 \%$ de locales y el $15 \%$ de hoteles reciclan los desechos; esto, pese a que en Costa Rica se cuenta con la Ley para la Gestión Integral de Residuos N. 8839 (Poder Legislativo, 2010), en la cual se indica claramente la obligación que tienen los entes generadores de residuos de separarlos desde la fuente, clasificarlos y entregarlos a un gestor autorizado o al sistema municipal. La falta de aplicación de esta ley no ayuda a corregir o prevenir la con- taminación marina que pueden generar dichos residuos; por el contrario, puede llegar a ocasionar el deterioro del paisaje, la contaminación del suelo y el agua por la percolación de cargas orgánicas de los diferentes lixiviados que se generan (Doria \& Vivas, 2016), igualmente puede generar malos olores por la descomposición de la materia orgánica.

De los establecimientos entrevistados (Fig. 4) se determinó que, para la disposición de las aguas residuales, el $9 \%$ de los locales comerciales cuenta con planta de tratamiento y utiliza, 
En relación con el uso de tanen mayor proporción, el tanque séptico (24\%), seguido por el drenaje; igualmente solo el $15 \%$ de los hoteles cuenta con planta de tratamiento, mientras el $81 \%$ con tanque séptico, para una producción anual de aguas negras de 147 $759 \mathrm{~m}^{3}$ para Nacascolo y $979718 \mathrm{~m}^{3}$ para Sardinal. Estas aguas residuales provenientes de los asentamientos humanos cercanos a la costa, en algunos casos pueden llegar a descargarse de forma directa o indirecta en la zona costera y al mar, contaminando las aguas de las playas utilizadas para la recreación. ques sépticos, TECHO (2014) señala que algunas veces estos no han sido diseñados o construidos de manera adecuada por lo que no cumplen con los requerimientos técnicos para su uso. Así mismo, Ruiz (2012) informa que, pese a que la mayor cobertura de servicios de saneamiento es con tanque séptico, esto no significa que dichas aguas residuales se dirijan a estos, ya que se ha comprobado que en muchos casos las aguas negras o provenientes de los servicios sanitarios son las que se disponen en estos sistemas, mientras

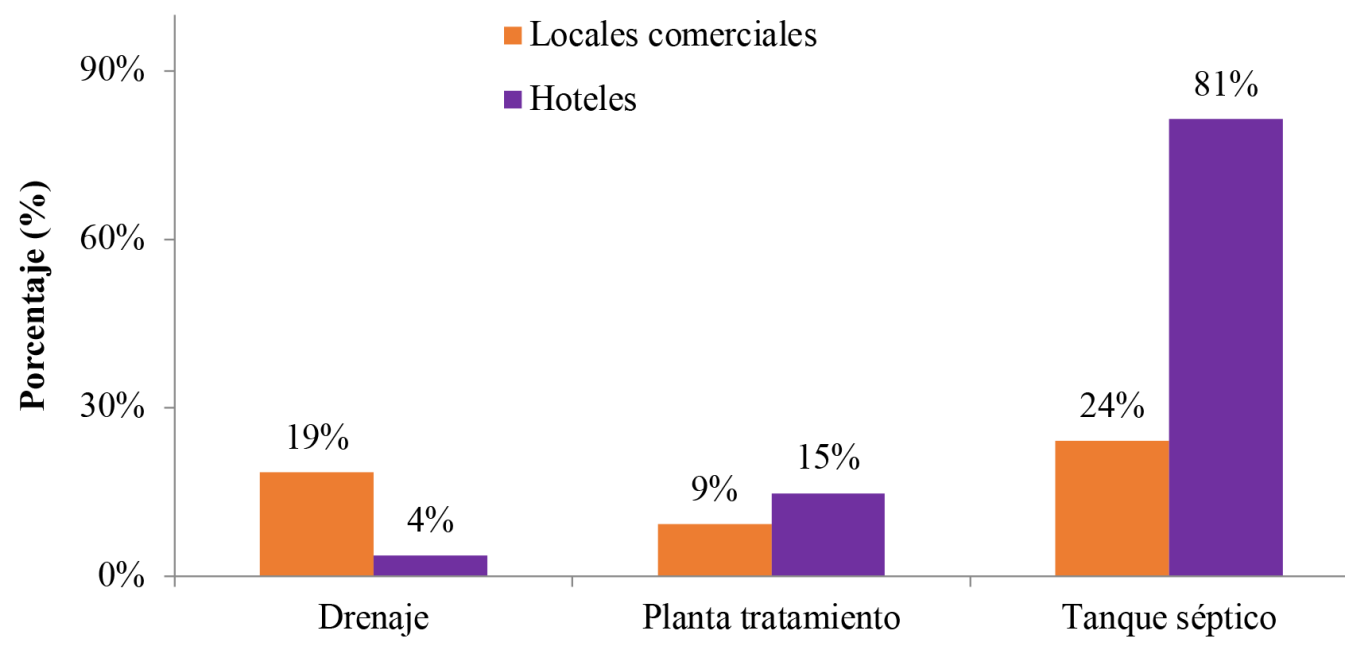

Tipo de disoposicón de residuos líquidos

Fig. 4. Distribución porcentual de la disposición de residuos líquidos, por categoría de las principales actividades económicas de los de los distritos de Nacascolo y Sardinal

Fig. 4. Percentage distribution of the liquid waste disposal, by category of the main economic activities of the Nacascolo and Sardinal districts 
que el resto se conduce directamente al alcantarillado pluvial. Lo anterior hace que las aguas de las alcantarillas contengan especialmente contaminantes orgánicos (Manzanares \& Ribaldi, 2017), derivados de las aguas residuales urbanas de las ciudades costeras con distinta densidad poblacional.

En este trabajo, en la zona costera del Golfo de Papagayo se ubicaron alrededor de 14 quebradas, drenajes y caños que recorren algunos cuadrantes urbanizados ubicados en las playas de El Coco y Hermosa que descargan directamente al mar, los cuales pueden contener organismos patógenos perjudiciales para la salud. Según su volumen, podrían constituir una de las principales fuentes de contaminación marina de la zona, favoreciendo el desarrollo de especies nocivas o tóxicas (Bustamante et al. 2016) y causando, de forma directa, diferentes grados de contaminación a lo largo de la línea de costa e impidiendo el desarrollo turístico al alterar la estética costera. Además, podría perjudicar el desarrollo de las comunidades marinas y perturbar las cadenas tróficas con grave riesgo a la salud pública, debido a la ingesta o contacto directo de aguas o alimentos contaminados.

Los resultados obtenidos del análisis de las muestras de agua recolectadas en diferentes playas para determinar su calidad higiénico-sanitaria indican que para los coliformes fecales, en época seca el rango de las concentraciones estuvo entre $<1.8$ $70 \mathrm{NMP} / 100 \mathrm{~mL}$, donde la estación 7 (playa Hermosa) obtuvo mayor concentración (Cuadro 3) clasificándose como clase "A" de buena calidad (Cuadro 2). En general, en la época seca, el $85 \%$ de las estaciones muestreadas tuvieron un rango "AA" considerada de excelente calidad $(<10)$, particularmente en febrero del 2018.

Cuadro 3. Clasificación de las playas de acuerdo con la concentración de coliformes fecales

Table 3. Classification of beaches by concentration of fecal coliforms

\begin{tabular}{lll}
\hline Clase & Calidad & $\begin{array}{l}\text { Concentración } \\
\text { CF } \\
\text { (NMP/100mL) }\end{array}$ \\
\hline AA & Excelente & $<10$ \\
A & Buena & $10-100$ \\
B & Regular & $101-240$ \\
C & Mala / No aptas & $>240-500$ \\
D & para la natación & $500-1000$ \\
\hline
\end{tabular}

Mora et al. (2012).

Para la época lluviosa, se presentaron tres condiciones de calidad: excelente "AA", buena "A" y regular "B". En octubre del 2017 se obtuvo un rango entre $<1.8-240 \mathrm{NMP} / 100 \mathrm{~mL}$. La playa Arenilla (estación 11) presentó la calidad higiénico-sanitaria menor (240 NMP/100mL); mientras que en mayo del 2018 la playa con menor calidad higiénico-sanitaria fue playas del Coco (estación 5) con 46 
NMP/100mL. Según la clasificación propuesta por Mora et al. (2012), se puede decir que todas las playas estudiadas son aptas para la recreación. Dichos resultados son similares a los reportados por Mora et al. (2012) para el período comprendido entre 1996 y 2011 y por Sánchez-Noguera et al. (2018) para el período de 2010 y 2011, en donde la calidad de las aguas de las playas analizadas en el Golfo de Papagayo estuvo entre excelente y buena.

Para los Enterococcus presentes en el agua, se encontró que tanto para la época seca como la lluviosa el rango fue de $<1.0$ a $305.0 \mathrm{NMP} / 100 \mathrm{~mL}$ (Cuadro 4 ), con lo que el $100 \%$ de las playas clasifica como de calidad apta para uso recreativo, de acuerdo con el límite permisible por la OMS (Díaz et al. 2010).

Tal y como se observa, la mayoría de las playas estudiadas presenta una calidad buena o apta para uso recreativo, lo cual puede deberse a que, al estar ubicadas en un golfo abierto, como lo es el Golfo de Papagayo, ayuda a que ocurra una mayor y rápida dispersión de los contaminantes. En el caso de playa Hermosa, el Coco y Arenilla, para coliformes fecales las concentraciones fueron de las más altas, lo cual pudo deberse a que en dichas playas existen algunas quebradas, drenajes y caños que recorren algunos

Cuadro 4. Número más probable de Enterococcus en las playas ubicadas en los alrededores del Golfo de Papagayo, durante la época seca y lluviosa Table 4. Most probable number of Enterococcus in the beaches along the Gulf of Papagayo, during dry and rainy seasons

\begin{tabular}{llcccc}
\hline \multirow{2}{*}{ Punto } & & \multicolumn{2}{c}{ Época seca } & \multicolumn{2}{c}{ Época lluviosa } \\
& & NMP/100 & mL & \\
& & nov-17 & feb-18 & oct-17 & may-18 \\
\hline 1 & Matapalo & 10.0 & $<1.0$ & 30.0 & $<1.0$ \\
2 & Matapalo & 63.0 & $<1.0$ & 135.0 & 10.0 \\
3 & Ocotal & 10.0 & 10.0 & 41.0 & $<1.0$ \\
4 & El Coco & 10.0 & 20.0 & $<1.0$ & 100.0 \\
5 & El Coco & 305.0 & 20.0 & 197.0 & $<1.0$ \\
6 & El Coco & 10.0 & $<1.0$ & 10.0 & $<1.0$ \\
7 & Hermosa & $<1.0$ & $<1.0$ & 97.0 & $<1.0$ \\
8 & Hermosa & 20.0 & $<1.0$ & 10.0 & $<1.0$ \\
9 & Panamá & $<1.0$ & $<1.0$ & $<1.0$ & $<1.0$ \\
10 & Panamá & $<1.0$ & 10.0 & 41.0 & $<1.0$ \\
11 & Arenilla & $<1.0$ & $<1.0$ & 30.0 & $<1.0$ \\
12 & Marina en Bahía Culebra & $<1.0$ & $<1.0$ & $<1.0$ & $<1.0$ \\
13 & Nacazcol & $<1.0$ & $<1.0$ & $<1.0$ & 10.0 \\
\hline
\end{tabular}


cuadrantes urbanizados y cuyas aguas pueden contener microorganismos. Especialmente en playas del Coco, donde se muestran los valores más altos para Enterococcus tanto en época lluviosa como en época seca.

Es importante destacar los esfuerzos que actualmente realiza el Instituto Costarricense de Acueductos y Alcantarillados, junto con otras instituciones, para que las zonas costeras de uso recreativo se hagan acreedoras al galardón Bandera Azul, el cual premia el esfuerzo y trabajo voluntario para la conservación y desarrollo de las playas, buscando siempre mejorar las condiciones higiénico sanitarias y en donde se evalúa, entre otras cosas, la concentración de coliformes fecales. Entre las playas que han recibido este galardón en esta zona de estudio están: Azul (Bahía Pez Vela), Ocotal, Manzanillo en Bahía Culebra, y Playa Hermosa, las cuales tienen una estrella y Playa Panamá que tiene dos estrellas (Chávez, 2017).

Según los resultados anteriormente expuestos, es importante recomendar al Instituto Costarricense de Acueductos y Alcantarillados, que incluya -dentro de los análisis bacteriológicos para el otorgamiento de este distintivo o galardón- el género Enterococcus, debido que es altamente resistente a condiciones salinas, lo que según Larrea-Murrell et al. (2013) lo hace un indicador bacteriológico más eficiente para evaluar la calidad del agua de mar para uso recreativo.
Por otra parte, debido a que, en algunas zonas costeras, el manejo inadecuado y disposición de residuos sólidos y líquidos es una de las principales causas de variación y trasformación del ambiente, por los malos olores, lixiviados de la basura, proliferación de insectos y otros vectores que pueden dañar la salud de las personas y el ambiente en general, es importante concientizar a las poblaciones de los cantones costeros de cuidar los alrededores de la zona marino-costera para que no exista un deterioro del medio ambiente.

\section{CONCLUSIONES}

Las principales fuentes de contaminación que impactan la zona marino-costera ubicada en los alrededores del Golfo de Papagayo provienen de actividades económicas netamente comerciales y domésticas. Estas generan residuos sólidos y líquidos de tipo ordinario. Se ubicaron fuentes puntuales de contaminación en el perímetro de la zona de estudio, constituidas por drenajes y caños que descargan directamente al mar.

Durante las giras realizadas por el perímetro de la zona de estudio se observó la presencia de drenajes y caños que descargan directamente sus aguas residuales al mar.

Las concentraciones de coliformes fecales y enterococos determinadas en las aguas de las playas analizadas aumentan en la mayoría de los 
puntos de muestreo durante la época lluviosa, lo cual podría indicar que estos grupos bacterianos son arrastrados desde los afluentes de aguas residuales a través de la escorrentía superficial debido a las lluvias.

Según la concentración de coliformes fecales y Enterococus, las playas analizadas se clasifican como aptas para uso recreativo. Sin embargo, es importante realizar monitoreos periódicos en estas playas, con el fin de prevenir o minimizar riesgos a la salud pública por enfermedades gastrointestinales, de la piel y otras, ya que la calidad higiénico-sanitaria de esta zona del Golfo de Papagayo ha disminuido una categoría (regular) desde el 2011, según lo reportado por Sánchez-Noguera et al. (2018).

\section{AGRADECIMIENTOS}

Al personal del Laboratorio de Química Marina (LABQUIMAR-UNA), por su colaboración en la aplicación de las encuestas. Al personal del HIDROCEC-UNA, por su colaboración en la aplicación de encuestas y al equipo evaluador, por su valiosa contribución.

\section{BIBLIOGRAFÍA}

APHA. American Public Health Association. (2012). Standard methods for the examination of water and wastewater $(22$ ed.). Washington D. C.: EE. UU.: Joint Editorial Board.
BIOMARCC-SINAC-GIZ. (2013). Análisis de vulnerabilidad de las zonas oceánicas y marino-costeras de Costa Rica frente al cambio climático. San José: Costa Rica: Proyecto Biodiversidad Marino Costera en Costa Rica, Desarrollo de Capacidades y Adaptación al Cambio Climático.

Bustamante, C., Fernández, M. C., Lugioyo, G. M. \& Álvarez, S. L. (2016). Comunidades fitoplanctónicas indicadoras del estado trófico en las Playas del Este, La Habana, Cuba. R. Cien. Mar. Cost., 8(2), 75-92. https://doi. org/10.15359/revmar.8-2.5

Chávez, A. (2017). Programa Bandera Azul Ecológica de Costa Rica, informe de galardonados BAE del año 2016. San José: Costa Rica: AyA.

Cortés J. (2017). Marine biodiversity baseline for Área de Conservación Guanacaste, Costa Rica: published records. ZooKeys, 652, 129-179. https:// doi:10.3897/zookeys.652.10427

Díaz, M., Rodríguez, C. \& Zhurbenko, R. (2010). Aspectos fundamentales sobre el género Enterococcus como patógeno de elevada importancia en la actualidad. R. Cubana Hig. Epidemiol., 48(2), 147-161.

Doria, C. \& Vivas, L. (2016). Fuentes terrestres de contaminación en la zona costera de La Guajira, Colombia. Rev. Invest. Agraria y Ambiental, 7(1), 123-138.

Duffy, D. C. \& Frazier, J. G. (2014). Seabird distribution in the Gulf of Papagayo, Costa Rica, during non-upwelling conditions. Mar. Ornithology, 42, 57-62.

Durán, G. (2016). Confección de mapas. Universidad Nacional, Guanacaste: Costa Rica. Centro de Recursos Hídricos para Centroamérica y el Caribe (HIDROCEC-UNA).

INEC. (2014). Evaluación Censo 2011. Recuperado en enero 25, 2017, disponible en http://www.inec.go.cr 
Jiménez, J. A. (2016). El domo térmico de Costa Rica: Un oasis de productividad frente a las costas del Pacífico centroamericano. Fundación MarViva, San José, Costa Rica. 17-19.

Larrea-Murrell, J. A., Rojas-Badía, M. M., Romeu-Álvarez, B., Rojas-Hernández, N. M. \& Heydrich-Pérez, M. (2013). Bacterias indicadoras de contaminación fecal en la evaluación de la calidad de las aguas: Revisión de la literatura. Revista CENIC. Ciencias Biológicas, 44(3).

León, S. \& Jiménez, J. (1998). Cuencas hidrográficas y el Golfo de Nicoya: Una revisión bibliográfica de procesos de degradación. Heredia: Costa Rica. Sin Editorial.

Manzanares, C. F. \& Ribaldi, A. F. (2017). Remoción de materia orgánica de agua residual sintética con filtros aerobios en medio sintéticos reciclable a escala piloto. Tesis profesional no publicada. Universidad Nacional del Centro del Perú.

May-Collado, L. J. \& Forcada, J. (2012). Small-scale estimation of relative abundance for the coastal spotted dolphins (Stenella attenuata) in Costa Rica: the effect of habitat and seasonality. Rev. Biol. Trop., 60, 133-142.

May-Collado, L. J., Amador-Caballero, M., Casas, J. J., Gamboa-Poveda, M. P., Garita-Alpízar, F., Gerrodette, T. \& Pérez, B. (2018). Ecology and Conservation of Cetaceans of Costa Rica and Panama. In M. R. Rossi-Santos \& C. W. Finkl (Eds.), Advances in Marine Vertebrate Research in Latin America (pp. 293-319). Cham, Germany: Springer.

Mora, D., Chávez, A. \& Portuguez, C. (2012). Calidad sanitaria de las aguas de playa de Costa Rica período 1996-2011. Laboratorio Nacional de Aguas. Instituto Costarricense de Acueductos y Alcantarillados.
Poder Legislativo. (2010). Ley para la gestión integral de residuos No. 8839. San José, Costa Rica: La Gaceta.

Reyes, V. (2016). Determinación de la eficiencia del aserrín y la fibra de coco utilizados como empaques para la remoción de contaminantes en biofiltros para el tratamiento de aguas residuales. Enfoque UTE, 7(3), 41-56.

Reyes, V., Sánchez, R., Chacón, D., Mora, R. \& Castro, R. (2015). Documento técnico con la propuesta de esquema o instrumentos económicos y financieros, con su estrategia, para la mejora de la recaudación de fondos para el PN Santa Rosa. Cedarena, SINAC, PNUD, Gef, Areas Marinas Protegidas: Costa Rica.

Ruiz, F. (2012). Gestión de las excretas y aguas residuales en Costa Rica. Situación actual y perspectiva. San José: Costa Rica. Instituto Costarricense de Acueductos y Alcantarillados.

Sánchez-Noguera, C., Jiménez, C. \& Cortés, J. (2018). Desarrollo costero y ambientes marino-costeros en Bahía Culebra, Guanacaste, Costa Rica. Rev. Biol. Trop. 66(1), 309-327. http://doi.org/ 10.15517/rbt.v66i1.33301

Socas, M. (2018). Contaminación por residuos: Islas de plástico Trabajo de fin de grado Escuela Politécnica Superior de Ingeniería, Sección de náutica, máquinas y radioelectrónica naval. Universidad de La Laguna.

TECHO. (2014). Informe del catastro nacional de asentamientos en condición de pobreza 2013. Recuperado el febrero 12, 2019, disponible en http://www.techo.org/paises/costarica/ 